\title{
ОСОБЕННОСТИ, ТЕНДЕНЦИИ И НАПРАВЛЕНИЯ РАЗВИТИЯ ИНВЕСТИЦИОННОЙ ДЕЯТЕЛЬНОСТИ ГОСУДАРСТВ-ЧЛЕНОВ ЕАЭС
}

\section{FEATURES, TRENDS AND DIRECTIONS OF DEVELOPMENT OF INVESTMENT ACTIVITIES OF THE EAEU MEMBER STATES}

\section{K. Usmanova}

Summary. The article discusses the main vectors for the development of investment activities in the EAEU. It is noted that in order to increase investment cooperation, it is necessary to form a single financial market in the EAEU. The urgency of the formation of a single financial market of the EAEU is argued. It is indicated that currently the EAEU is characterized by significant differences in the laws governing investment activities. It is concluded that measures are needed to harmonize and unify the investment laws of the EAEU member states. The distribution of funds from the EFSD and the EDB must be carried out in a more balanced mode and investment in projects related to $R \& D$, digital, green economy must be intensified. It is noted that the EAEU lags behind the EU, the USA, the PRC, and this increases the technological and innovation gap from the leaders in these areas.

Keywords: EAEU, investment, foreign direct investment, GDP, single financial market, digital economy, green economy.

\author{
Усманова Камила Надировна \\ Аспирант, Финансовый университет при \\ Правительстве РФ \\ kamatwist@yandex.ru
}

Аннотация. В статье рассмотрены основные прогнозируемые векторы развития инвестиционной деятельности в ЕАЭС. Отмечается, что для повышения эффективности инвестиционного сотрудничества в ЕАЭС необходимо формирование единого финансового рынка. Аргументируется актуальность формирования единого финансового рынка ЕАЭС. Указывается, что в настоящее время ЕАЭС присущи значительные различия во внутренних законодательствах стран-участниц данного регионального объединения, регулирующих инвестиционную деятельность. Делается вывод, что необходимы мероприятия по гармонизации и унифицированию инвестиционных законодательств стран-участниц ЕАЭС. Распределение средств из ЕФСР и ЕАБР необходимо осуществлять в более взвешенном режиме и активизировать инвестирование проектов, связанных с НИОКР, цифровой, «зеленой» экономикой. Отмечается, что ЕАЭС отстает от ЕС, США, КНР, а это увеличивает технологический и инновационный разрыв с лидерами в данных сферах.

Ключевые слова: ЕАЭС, инвестиции, прямые иностранные инвестиции, ВВП, единый финансовый рынок, цифровая экономика, «зеленая» экономика.

совых услуг опережают аналогичные в остальных странах-участницах [4]. В связи с этим, требуется приведение всех составляющих в сбалансированное состояние.

Определенные результаты в инвестиционной деятельности ЕАЭС однозначно достигнуты, что отмечается в многочисленных отчетах внутренних и сторонних экспертов [5]. На фоне несомненных достижений участниками ЕАЭС по финансовой, инвестиционной интеграции все еще затруднительно спрогнозировать четкие перспективы развития общего финансового рынка ЕАЭС [6]. Финансовое развитие в ЕАЭС характеризуется достаточно высокой степенью неравномерности относительно территориального критерия, сегментации сложившихся рынков. Поэтому при углублении финансовой интеграции требуется учитывать возможности каждой страны-участницы.

Существует определенная асимметричность в проявлении инвестиционных аспектов сотрудничества стран-участниц. Российской Федерации по-прежнему отводятся лидирующие позиции в этом процессе [7; 8]. 


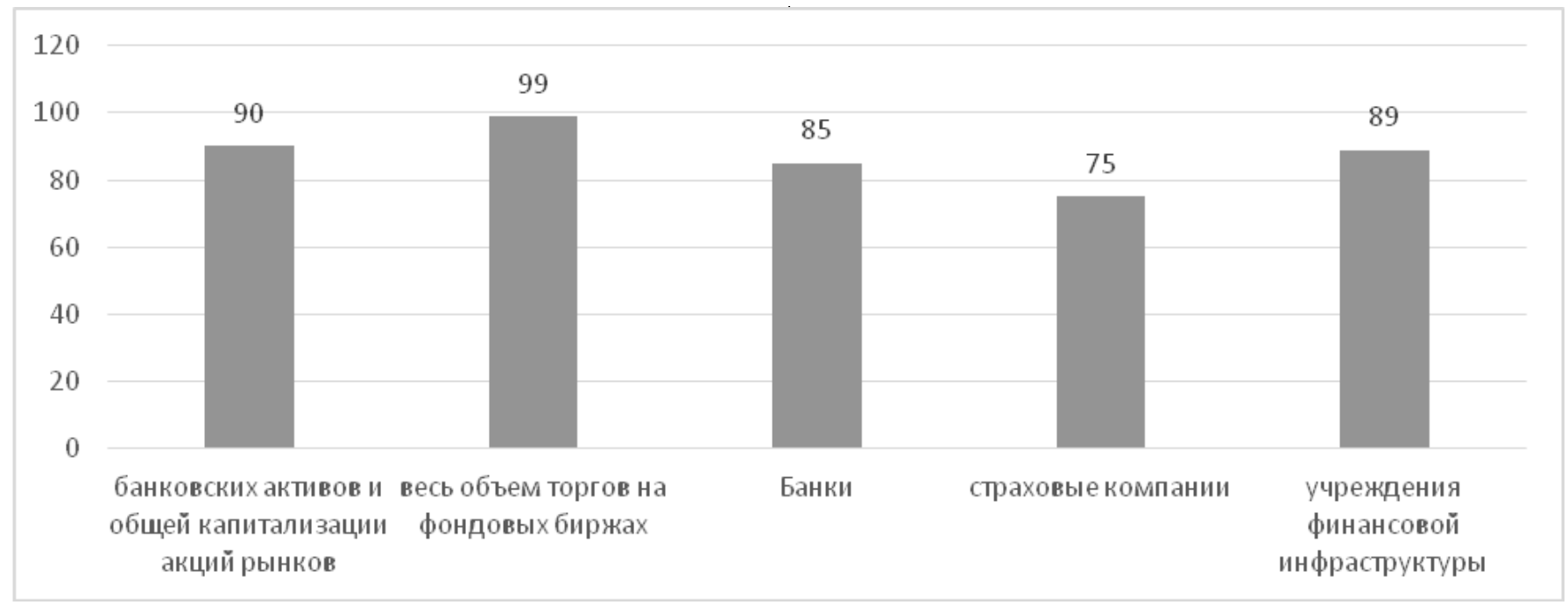

Рис. 1. Доля общих финансовых активов стран ЕАЭС в России

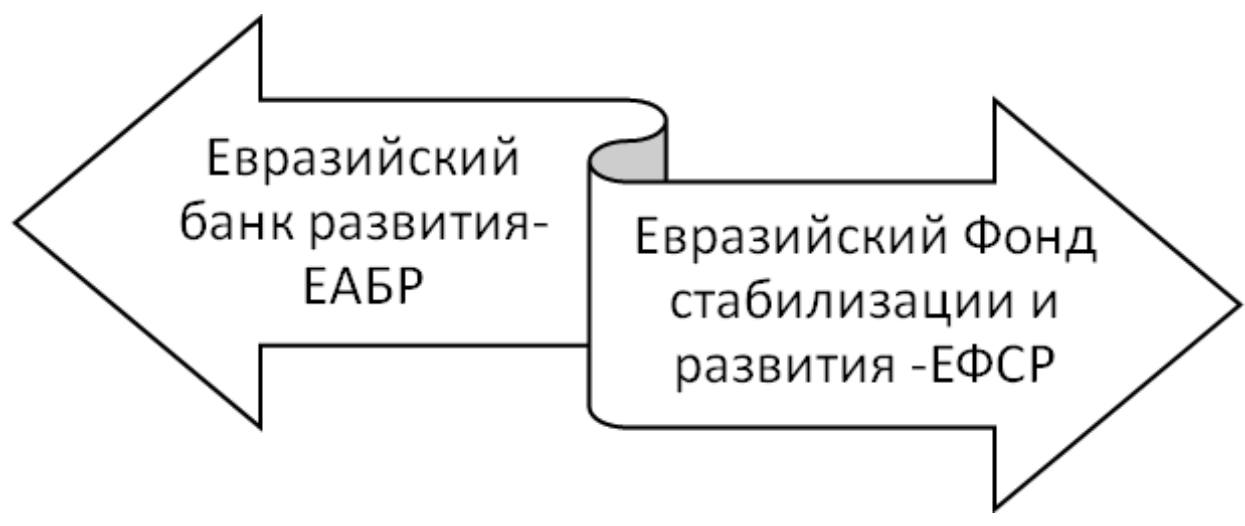

Рис. 2. Институциональные финансовые организации ЕАЭС

Так, преобладающая доля общих финансовых активов стран ЕАЭС сосредоточена в России (более 90\% банковских активов и общей капитализации акций рынков), а также практически весь объем торгов на фондовых биржах, примерно 85\% банков, 75\% страховых компаний, 89\% учреждений финансовой инфраструктуры (рисунок 1) [9; 10].

Возникающие в ЕАЭС в процессе формирования общего финансового рынка капиталов затруднения вызывают вертикальную реализацию «сверху». В настоящее время происходит этап гармонизации национальных законодательств и достижения максимально возможной координации денежно-кредитной и финансовой политик государств-членов, дополненных финансовыми решениями, которые соотносятся с вызовами, актуальными для ЕАЭС и способными усилить финансовую интеграцию, основывающуюся на новых принципах, значимых для современного общества [11].
Такие решения продиктованы целями устойчивого развития, что находится в соответствии с мировыми тенденциями, совпадающими по устремлению с интересами всех участниц ЕАЭС. В связи с этим, целесообразно обратиться к перспективам развития единого финансового рынка в рамках ЕАЭС, анализируя связанные с этим предпосылки в контексте специфики текущего этапа формирования приоритетов и особенностей финансовых систем стран-участниц[13].

Соглашения о партнерстве и инвестиционном сотрудничестве в рамках ЕАЭС разрабатываются индивидуально, и в них учитываются специфические условия, потребности и интересы сторон, которые выходят за рамки экономического подхода. Преимущественно, в данном интеграционном объединении инвестиционная деятельность осуществляется при помощи двух основных институциональных финансовых организаций (рисунок 2): 
ЕАБР - международная финансовая организация, созданная для содействия экономическому росту стран-участниц, расширения торгово-экономических связей между ними и поддержки интеграции в ЕАЭС посредством инвестиций. Банк учрежден в 2006 г.[14].

ЕФСР, созданный в 2009 г., накопил большой опыт в предоставлении кредитов для финансовой поддержки стран-участниц Фонда, в реализации антикризисных и стабилизационных программ, а также инвестиционных кредитов для крупных инфраструктурных проектов. Государства, входящие в ЕАЭС, посредством своего слаженного финансового, инвестиционного сотрудничества снижают дисбаланс в макроэкономике, формируют устойчивую базу для долгосрочного экономического роста данного интеграционного объединения. Формирование ЕФСР имело целью в свое время преодоление отрицательных тенденций финансового кризиса 2008 г. и обеспечение экономической устойчивости ЕАЭС. Исследования различных международных финансовых учреждений показывают, что имеются риски для устойчивого развития субъектов финансовой деятельности.

Пандемия явилась мощным фактором вызова для государств-членов, с последствиями которого и предназначены справиться ЕАБР и ЕФСР, усиливающие операционную эффективность, расширяющие сферу макроэкономических экспертиз и укрепляющие диалог с государствами-членами. Эффективность работы данных организаций зависит от корректирующих стратегий результатов анализа функционирования национальных экономик и потребностей стран-участниц [15].

В современной обстановке возросла роль региональных финансовых механизмов (далее - РФМ) благодаря их оперативности и соответствию региональному контексту. Новые РФМ расширили сеть безопасности финансовой деятельности на 1,1 трлн. долл. и расширили до 43 стран. В 2019 г. объем кредитования ЕФСР составлял 5407,5 млн. долл. или 6,4\% от совокупного ВВП стран-заемщиков. Это было эквивалентно 83,5\% их обычного доступа к ресурсам МВФ. В 2010-2018 гг. ЕФСР выделил около 20\% от общего объема финансирования, полученного от всех международных финансовых учреждений (МФУ) по странам-заемщикам. Чистые потоки из ЕФСР и Всемирного банка сопоставимы и эквивалентны 0,28\% и 0,27\% совокупного ВВП стран ЕАЭС и Таджикистана на 2010-2020 гг[16].

ЕФСР имеет расширенный мандат на поддержку как макростабилизации, так и развития. Это связано с взаимосвязью макростабилизации и специфики долгосрочных целей развития стран, входивших в Советский Союз, в которых наблюдается существенное ухудшение производственной базы и качества инфраструктуры. Первые два уровня глобальной сети финансовой безопасности (далее - НСФБ, The Global Financial Safety Net - GFSN) (международные резервы и двусторонний своп центрального банка договоренностей) в большинстве случаев являются не вполне недостаточными для того, чтобы страны-получатели ЕФСР могли эффективно противостоять финансовым вызовам [16-18].

ЕАБР осуществляет в ЕАЭС финансирование масштабных инвестиционных проектов в виде долгосрочного кредитования государственных, частных предприятий, участия в уставном капитале организаций, выпуска гарантий, финансирования инвестфондов и финансовых институтов с поддержкой ими предприятий реального сектора и торговых операций. Обновленная стратегия ЕАБР сосредоточится на крупных трансграничных инвестиционных проектах. Ожидается вложение инвестиций объемом 10,9 млрд. долл. в ближайшие 5 лет. Новыми инвестиционными проектами являются транспортный и цифровой коридор Европа - Западный Китай, единая товаропроводящая система ЕАЭС +, водно-энергетический комплекс Центральной Азии [19].

В перспективе Советом ЕАБР планируется разработка уникальной стратегии для каждого члена ЕАЭС с учетом его макроэкономических особенностей. Стратегия ЕАБР направлена на охват финансовыми операциями Армении, Кыргызстана и Таджикистана с объемом инвестиций до 500 млн. долл. Пятилетняя стратегия ЕАБР включает формирование единого цифрового пространства ЕАЭС +, цифровых компетенций и инфраструктуры. Утвержден Фонд цифровых инициатив (2020 г.) ЕАБР, 20 инвестиционных проектов цифровой направленности находятся на стадии рассмотрения (например, мобильное приложение COVID-19 Free Travel для межстрановой проверки данных теста ПЦР путешественников в ЕАЭС). Следующим приоритетом ЕАБР является поддержка развития «зеленой» экономики. В 2020 г. ЕАБР подписал 18 новых проектных соглашений на сумму 1,3 млрд. долл. Инвестиционный портфель ЕАБР возрос до 5,510 млрд. долл. Чистая прибыль в 2020 г. составила 32,6 млн. долл.

На экономику стран-членов Фонда влияет ряд глобальных, региональных и национальных экономических тенденций. Страны Фонда, учитывая относительный размер их экономик, демонстрируют высокую степень зависимости от мировых экономических тенденций: роста мировой экономики, состояния внешней торговли.

На рисунке 3 представлены основные виды проектов, финансируемых ЕФСР: 


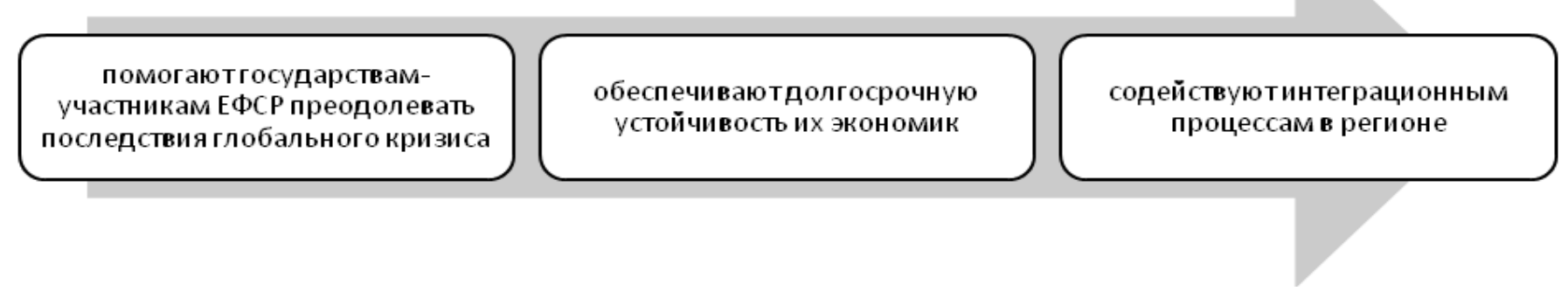

Рис. 3. Виды проектов, финансируемых ЕФСР

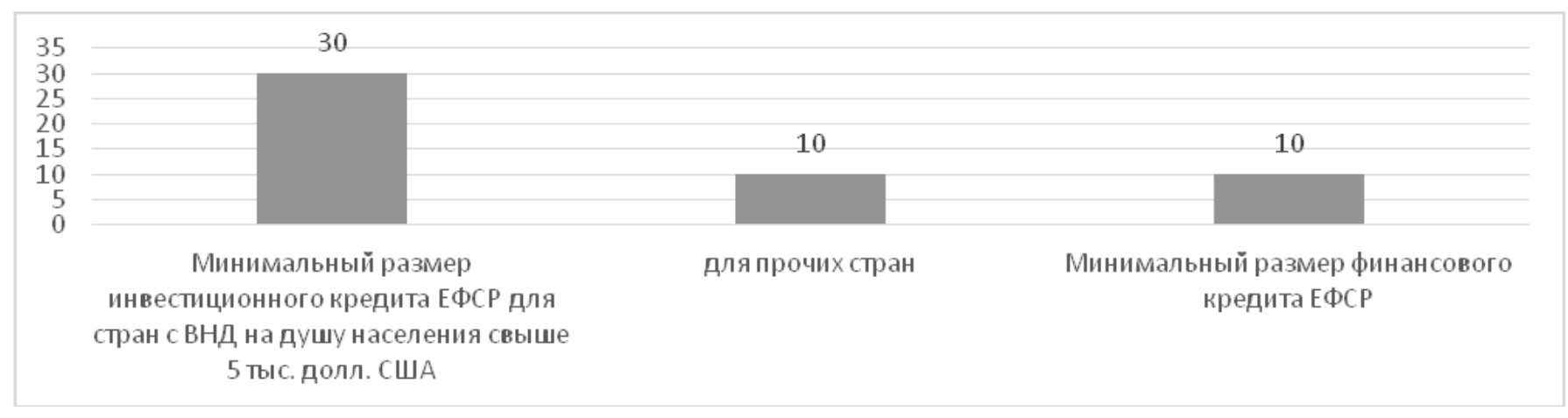

Рис. 4. Размеры кредитов, выделяемых ЕФСР, млн. долл. США

Это могут быть финансовые кредиты правительствам стран-участниц ЕФСР на поддержку бюджета, платёжного баланса и курса национальной валюты, инвестиционные кредиты государствам или компаниям, осуществляющим межгосударственные инвестиционные проекты. Обязательное условие финансирования ЕФСР - невозможность привлечения рыночного финансирования для реализации проекта в полном объеме (рисунок 4).

В середине 2019 г. объем кредитования ЕФСР составлял 5407,5 млн. долл. США или 6,4\% от совокупного показателя ВВП стран-заемщиков. Это было эквивалентно $83,5 \%$ от их обычного доступа к ресурсам МВФ. В период 2010-2020 гг. ЕФСР выделил более 20\% от общего объема финансирования, полученного от всех международных финансовых учреждений (МФУ) по странам-заемщикам. Чистые потоки из ЕФСР и Всемирного банка сопоставимы и эквивалентны 0,28\% и 0,27\% совокупного ВВП вышеупомянутых стран на 2010-2020 гг., соответственно[20].

ЕФСР явился одним из вновь созданных региональных финансовых соглашений РФМ после мирового финансового кризиса. В отличие от других фондов стабилизации и развития имеет расширенный мандат на поддержку как макростабилизации, так и целей развития. Это связано с сильной взаимосвязью макростабилизации и специфики долгосрочных целей развития стран постсоветского пространства. К последним относятся существенное ухудшение производственной базы наряду с продолжающимся снижением качества инфраструктуры.

Создание Фонда в 2009 г. было важным и необходимым шагом в развитии финансовой архитектуры региона. Прошло более десяти относительно стабильных лет, и риски макроэкономической дестабилизации в очередной раз показали возрастающую динамику. Вероятность негативных шоков, особенно в мировой торговле и при низких темпах экономического роста в крупных экономиках, резко увеличилась.

Создание единого финансового рынка в пространстве ЕАЭС позволит добиться синергии от реализации региональной повестки дня. Ожидается, что реализация совместных инвестиционных проектов стран-участниц ЕАЭс будет способствовать общему экономическому росту, увеличению занятости населения в отраслях, в которых размещаются внутренние и внешние прямые инвестиции, повышению производительности в приоритетных областях. Гармонизированное регу- 
лирование финансовых рынков должно стать одним из начальных направлений сотрудничества с целью создания единого рынка финансовых услуг в рамках ЕАЭС и обеспечения недискриминационного доступа к национальным финансовым рынкам каждого из государств-членов. Государства-члены ЕАЭС уже вступили в начальную стадию развития Евразийского общего рынка финансовых услуг.

Значительную часть работы должен выполнить наднациональный орган регулирования финансовых рынков, который должен быть создан к 2025 году в соответствии с Договором о ЕАЭС. Такая финансовая интеграция в ЕАЭС осуществляется в течение ограниченного периода времени, и многие ключевые шаги еще предстоит сделать. Существующий уровень развития национальных рынков крайне неоднороден и требует дальнейшего развития.

\section{ВывО $\triangle \mathrm{b}$}

1. В результате выполненного исследования установлено, что инвестиционная деятельность является важной составляющей интеграционного взаимодействия в ЕАЭС. Существование ЕврАзЭС заложило основу для выработки обширной и достаточной качественной нормативной базы, регулирующей многогранные аспекты торго- во-экономического сотрудничества стран-участниц ЕАЭС в настоящее время. Сохраняются значительные расхождения в инвестиционных законодательствах стран-участниц ЕАЭС. Данное обстоятельство препятствует интенсификации инвестиционной деятельности. Схожесть структур институциональных образований, подходов в управлении инвестиционной деятельностью, подготовке инвестиционных проектов для рассмотрения их на предмет финансирования ЕАБР оказывают способствующее воздействие на ускорение принятия инвестиционных проектов и их запуск.

2. Несмотря на задекларированные в уставах ЕАБР ценности и стремления к Выполнению ЦУР, на практике отсутствует реализация данного направления. Отмечается слабое взаимодействие основных финансовых учреждений ЕАЭС с международными структурами.

3. Распределение средств из ЕФСР необходимо осуществлять в более взвешенном режиме и активизировать инвестирование проектов, связанных с НИОКР, цифровой, а также «зеленой» экономикой, в связи с тем, что имеет место значительное отставание ЕАЭС от ЕС, а также от США, КНР, что ставит страны-участницы ЕАЭС в аутсайдерское положение, увеличивая технологический и инновационный разрыв от лидеров в данных сферах.

\section{ЛИТЕРАТУРА}

1. Kasyanov R.A. The EU Experience as a Model for the Development of a Single Financial Market Regulation in the Eurasian Economic Union (EAEU) European Company and Financial Law Review https://doi.org/10.1515/ecfr-2019-0021

2. Главы национальных банков государств ЕАЭС подписали Соглашение о гармонизации законодательства в сфере финансов // Официальный сайт Евразийской экономической комиссии. - 19.09.2018. — URL: http://www.eurasiancommission.org/ru/nae/news/Pages/19-09-2018-2.aspx (дата 0бращения: 05.10.2021)

3. Касьянов Р.А. Регулирование рынка финансовых услуг по праву ЕС и ЕАЭС: дисс. ... д-ра юрид. наук. 12.00 .10 / Касьянов Рустам Альбертович, М., 2019. 554 c.

4. Perepelitsa D.G., et al. Issues in and Prospects for the Formation of the EAEU's Common Financial Market and Its Infrastructure. 2018. Vol. 39 (Number 41): pp. 34-41.

5. Винокуров Е., Демиденко М., Коршунов Д. Потенциальные выгоды и издержки валютной интеграции в Евразийском экономическом союзе // ВопроСы экономики. 2017. - № 2. С. 75-96.

6. Центр интеграционных исследований ЕАБР (ЦИИ ЕАБР) (2017) Мониторинг взаимных инвестиций в странах СНГ — 2017 Доклад № 45 Санкт-Петербург: ЦИИ ЕАБР [Электронный ресурс]: https://eabrorg/analytics/integration-research/cii-reports/monitoring-vzaimnykh-investitsiyv-stranakh-sng-2017/ (дата обращения 21.10.2021)

7. Львова Н.А., Воронова В.В. Модальность устойчивого развития финансового рынка ЕАЭС // Проблемы современной экономики.—2019.—№ 3 (71). - С. 69-74.

8. Квашнин Ю.Д. АЭС в восприятии западного научно-экспертного сообщества // Контуры глобальных трансформаций: политика, экономика, праB0. - 2019. - № 12(2).-С. 212-227.

9. Субъекты финансового сектора и основнеы показатели их деятельности. [Электронный ресурс]: URL: http://www.eurasiancommission.org/ru/act/ integr_i_makroec/dep_stat/fin_stat/time_series/Pages/fin_organizati ons.aspx (дата обращения 10.10.2021)

10. Фальцман В.К. 0 преодолении вызовов России // Проблемы прогнозирования. - 2020.-№ 1. - С.60-70.

11. Финансовая политика в рамках Евразийской интеграции [Электронный ресурс]: URL: http://www.eurasiancommission.org/ru/Documents/EEC_ finpolit_150629_2.pdf; 
12. Galushko, Dmitriy V. Monetary and financial integration of states: Eurasian regional perspective. Financial Law Review, 2019, Issue 14 (2), p. 1-13, cze. 2019. ISSN2299-6834. <https://www.ejournals.eu/FLR/2019/Issue-2/art/14554/>. doi: https://doi.org/10.4467/22996834FLR.19.005.10766.

13. Lvova N., Rakhimov Z, Voronova N., Darushin I. The EAEU Common Financial Market: What are the Prospects of Sustainable Development? International Conference on Economics, Management and Technologies 2020 (ICEMT 2020) Advances in Economics, Business and Management Research, volume 13. p. 134-143.

14. Konopelko A. Eurasian Economic Union: a challenge for EU policy towards Kazakhstan. Asia Eur J 16, 1-17 (2018). https://doi.org/10.1007/s10308-017-0480 7

15. Vinokurov E., Efimov A., Levenkov A. The Eurasian Fund for Stabilization and Development: A Regional Financing Arrangement and Its Place in the Global Financial Safety Net // Eurasian Development Bank, 2019

16. Eurasian development bank strategy for the period from 2018 to 2022 [Электронный ресурс]: https://eabr.org/upload/iblock/d06/FINAL_eng_strategy.pdf (дата обращения 10.10.2021)

17. Vinokurov, E. and Levenkov, A. (2021) The global financial safety net: Evolution of the anti-crisis function in the global financial architecture. Voprosy Ekonomiki, 5:26-42. (In Russian). https://doi.org/10.32609/0042-8736-2021-5-26-42

18. EFSD Working Paper WP/19/1 "The Eurasian Fund for Stabilization and Development: A Regional Financing Arrangement and Its Place in the Global Financial Safety Net"

19. Kring, W., Gallaher, K. (2019) Strengthening the Foundations? Alternative Institutions for Finance and Development. Development and Change, 50(1): 3-23.

20. Eurasian Development Bank to Focus on Major Cross-Border Investment Projects Over Next Five Years [Электронный ресурс]: https://astanatimes.com/2021/07/ eurasian-development-bank-to-focus-on-major-cross-border-investment-projects-over-next-five-years/ (дата обращения 7.10.2021)

(c) Усманова Камила Надировна ( kamatwist@yandex.ru ).

Журнал «Современная наука: актуальные проблемы теории и практики»

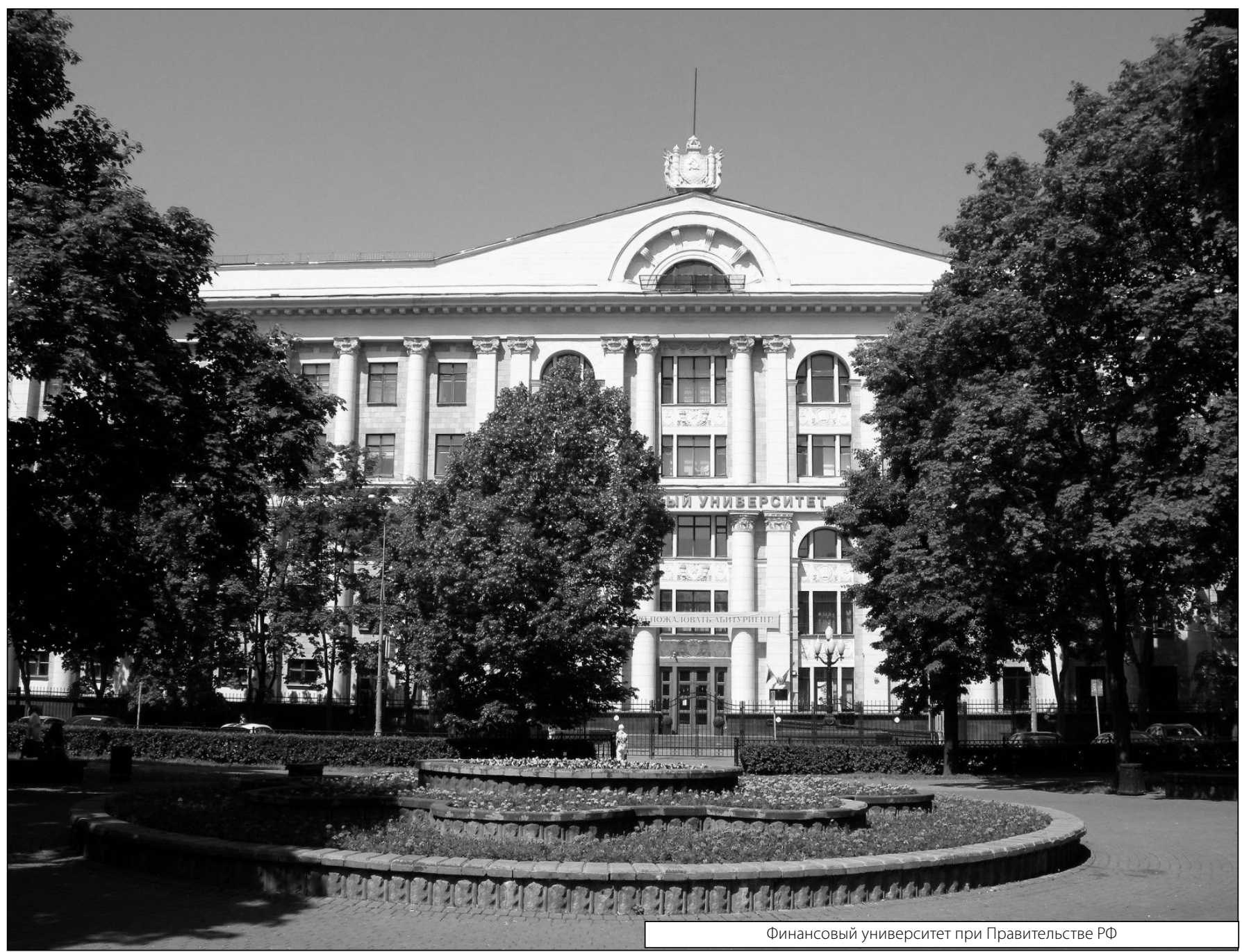

